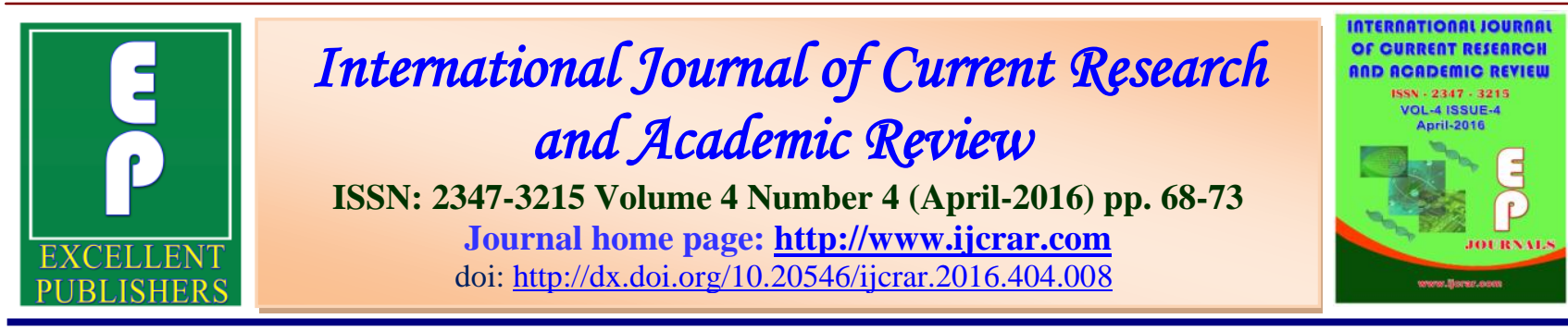

\title{
Formulation and Evaluation of Gel of Leaf Extract of Jasminum grandiflorum
}

\author{
Lincy Joseph $^{1 *}$, Mathew George ${ }^{2}$, Shweta Agrawal $^{3}$ and Prabha Mathews ${ }^{1}$ \\ ${ }^{1}$ Department of pharmaceutical Chemistry, Pushpagiri College of Pharmacy, Thiruvalla, \\ 689107, Kerala, India \\ ${ }^{2}$ Department of Pharmacology, Pushpagiri College of Pharmacy, Thiruvalla, 689107, Kerala, \\ India \\ ${ }^{3}$ Department of Pharmacognosy, School of Pharmaceutical Sciences, Jaipur National \\ University, Jaipur-302050, Rajasthan, India \\ *Corresponding author
}

\section{KEYWORDS}

Jasminum

grandiflorum,

Formulation of gel,

Evaluation of gel,

Screening for

antibacterial activity.

\section{A B S T R A C T}

Medicinal plants are used in the Ayurvedic and Unani System of medicine besides use of many plants in the folk remedies. Medicinal plants are used in different countries as sources of many potent and powerful medicines. Semi solid dosage form is advantageous in terms of its easy application, rapid formulation and ability to topically deliver a wide variety of drug molecules. Topical drug delivery gained popularity because it provides a largest surface area, avoids first pass effects and gastrointestinal irritation. Topical gel formulations provide a suitable delivery system, because they are less greasy, can be easily removed from skin and provide a successful approach in delivering combination products. In the present study gel was formulated from aqueous extracts of Jasminum grandiflorum, and evaluated its physical, chemical and biological properties. The physical evaluation of formulated gel for parameters like $\mathrm{pH}$, refractive index, specific gravity complies with the standard specification. The chemical investigation of gel showed the presence of various phytoconstituents like phytosterol, phenols, tannins, flavanoids, alkaloids, carbohydrates, saponins terpenes. The biological evaluation was done by testing the gel against various microorganisms and was found most effective against $S$ aureus.

\section{Introduction}

Plants are the traditional source for many of the chemicals used as pharmaceuticals, biochemicals, fragrance, food colour and flavours. Most valuable phytochemicals are secondary metabolites of plants and possess sufficient chemical or structural complexity (Kulkani PH, Ansari Shahida, 2004). According to world health organization, medicinal plants are the best source to obtain a variety of newer herbal drugs. 
Jasminum grandiflorum, also called chameli,chambeli and mallige belonging to family Oleaceae, is a plant with fragrant flowers. It is found all over India, especially in the temperate regions and on the temperate Himalayas (CSIR, 2004). The Chameli leaves contain resin, salicylic acid, jasminine an alkaloid and an astringent principle (Asilbekova DT, Gusakova SD et al., 1999).

The leaves of Jasminum grandiflorum is used in folk medicine for treating ulcerative stomatitis, toothache, skin diseases,ulcers, wounds, and also as gargles. It has been reported to possess antiulcer (Umamaheswari M, Asok Kumar K, 2007), in vitro antioxidant (Umamaheswari M, Asok Kumar K, 2007), anti-lipid peroxidation (Kolanjiappan K, Manoharan S, 2005) and spasmolytic activity. So far no significant research work has been done on the study of the antimicrobial activity of Jasminum grandiflorum. The formulation of the drug into a suitable topical drug delivery system depending on the physiochemical properties of the extract will produce maximum pharmacological action.

The formulation of a suitable semisolid dosage form involves the selection of an appropriate drug carrier system, with a special emphasis on the drug's physicochemical properties and required therapeutic application.

Semisolids constitute a significant proportion of pharmaceutical dosage dosage forms. They serve as a carrier for drugs that are topically delivered (Remington, 1995). Because of their peculiar rheological behavior, semisolids can adhere to the applied surface for sufficiently long time before they are washed off. This property helps prolong drug delivery at the application site. Semi solid dosage form is advantageous in terms of its easy application, rapid formulation and ability to topically deliver a wide variety of drug molecules. Topical drug delivery gained popularity because it provides a largest surface area, avoids first pass effects and gastrointestinal irritation (Lachman L, Lieberman HA, 1991).

Gels are semisolid systems that consist of either suspensions of small inorganic particles or large organic molecules interpenetrated by a liquid. Gels can be either water based (aqueous gels) or organic solvent based (organogels) (Aulton ME, 1995). Topical gel formulations provide a suitable delivery system, because they are less greasy, can be easily removed from skin and provide a successful approach in delivering combination products. Therefore in the present study a gel system has been designed to deliver the drug topically.

\section{Materials and Methods}

\section{Plant Materials and Extraction}

Aerial parts of Jasminum grandiflorum were collected from Jaipur and authenticated by Rajasthan University (RUBL/RAJ/DRUG Authenticated 2008.09/20531) Jaipur (Rajasthan). Aerial parts of Jasminum grandiflorum were dried in shade at room temperature, powered and extracted by soxhlet continuous extraction method using aqueous solvent.

\section{Formulation of Gel (Barry BW, 1983)}

The aqueous extract $(25 \mathrm{~g})$ that was prepared in the extraction procedure was dissolved in $1 \mathrm{~L}$ of distilled water and kept for 72 hours, and filtered through 100mesh sieve. 1\% Carbopol was added as gelling agent and mixed properly and set aside for 72hours. After mixing for 3-4 hours added methyl 
paraben sodium $(0.1 \%)$, propyl paraben sodium $(0.5 \%)$, sodium citrate $(0.1 \%)$ etc as stabilizers and mixed for $2 \mathrm{hrs}$ and kept aside for $48 \mathrm{hrs}$. after which $1 \%$ glycerin was added and mixed for $2 \mathrm{hrs}$ and this was mixed with dry ethanolamine $(0.1 \%)$ and mixed for $3 \mathrm{hrs}$ and again kept for $48 \mathrm{hrs}$. The gel was hence formulated and subjected for further evaluation.

\section{Evaluation of Gel (Gupta, Garg, 2002)}

\section{Physical Evaluation}

Measurement of $\mathrm{pH}$ : The $\mathrm{pH}$ of gel formulation was determined by using digital $\mathrm{pH}$ meter. $1 \mathrm{~g}$ of gel was dissolved in $100 \mathrm{ml}$ distilled water and stored for $2 \mathrm{hrs}$. The measurement of $\mathrm{pH}$ of gel was done.

Refractive index: R.I of gel formulation was determined by this method. Weigh $25 \mathrm{ml}$ volumetric flask, and fill it with gel and again weigh. Then obtain weight difference between both flasks and calculate specific gravity using the formula,

Specific gravity $=$ weight difference/ 0.996 , Where 0.996 is specific gravity of water.

\section{Chemical Evaluation}

Chemical involves the detection of active and inactive ingredients in the gel. Performed qualitative test for determination of chemical constituents in gel.

\section{Phytochemical screening of gel}

Phytochemical screening of gel have been done for compounds like carbohydrates, alkaloids, steroids, saponins, phenols and tannins etc (Sadhu SK, Khan MS, 2007).

\section{Biological Evaluation}

Biological evaluation was done by testing aqueous gel for antibacterial activity by disc diffusion method.
Screening for antibacterial activity of aqueous gel (Priya Joy, Patric RD, 2008).

In vitro antibacterial activity was screened by disc diffusion method using muller hinton agar (NA) obtained from B.LAL Institute of Technology.

Pure cultures of bacteria maintained on Muller Hinton agar medium at the B.LAL Institute of Technology were used. The test organisms used for screening are, E. coli (ATCC25922), Staphylococcus aureus (ATCC29213), Pseudomonas aeruginosa (ATCC27853), Basillus cereus(ATCC6633)

The NA plates were prepared by pouring $15 \mathrm{ml}$ of molten media into sterile petriplates. The plates were allowed to solidify and $0.1 \%$ inoculums suspension was swabbed uniformly and the inoculum was allowed to dry for 5 minutes. The aqueous gel was loaded on $5 \mathrm{~mm}$ sterile disc till saturation. The loaded disc was placed on the surface of medium and the compound was allowed to diffuse for 5 minutes and the plates were kept for incubation at $37^{\circ} \mathrm{C}$ for $24 \mathrm{hrs}$. At the end of incubation, inhibiton zones formed around the disc were measured with transparent ruler in millimeter. This study was conducted using ciprofloxacin $(5 \mathrm{mcg})$ as standard drug.

\section{Results and Discussion}

Formulated gel was brown in colour. Results of physical, chemical and biological evaluation are as follows.

Physical evaluation
a. $\mathrm{pH}$ of gel $=6.2$
b. Refractive index $=1.008$
c. Specific gravity $=0.990$ 
Int.J.Curr.Res.Aca.Rev.2016; 4(4): 68-73

\section{Chemical Screening of Gel}

The results of phytochemical analysis of gel is given in Table: 1

\section{Biological Evaluation of the Drug}

Was done by screening for antibacterial activity. The results for screening of anti bacterial activity is given in Table $: 2$.
The objective of present study was to formulate and evaluate gel for topical application prepared using aqueous extracts of Jasminum grandiflorum. Topical dermatologic products are intended for localized action on one or more layers of the skin. Topical gel formulations provide a suitable delivery system for drugs because they are less greasy and can be easily removed from the skin.

Table.1 Phytochemical Analysis of Gel

\begin{tabular}{|c|c|c|c|}
\hline $\begin{array}{l}\text { SI } \\
\text { no. }\end{array}$ & Chemical Constituent & Test & Result \\
\hline \multirow[t]{4}{*}{1} & \multirow[t]{4}{*}{ Alkoloids } & 1. Mayer's test & + \\
\hline & & 2. Dragendroff's test & + \\
\hline & & 3. Wagner's test & + \\
\hline & & 4. Hager's test & + \\
\hline \multirow[t]{2}{*}{2} & \multirow[t]{2}{*}{ Carbohydrates } & 1. Molisch's test & + \\
\hline & & 2. Benedict's test & + \\
\hline \multirow[t]{2}{*}{3} & \multirow[t]{2}{*}{ Glycosides } & $\begin{array}{l}\text { 1. Modified Bontrager's } \\
\text { test }\end{array}$ & - \\
\hline & & 2. Legal test & - \\
\hline 4 & Saponins & 1. Foam test & + \\
\hline \multirow[t]{2}{*}{5} & \multirow[t]{2}{*}{ Phytosterol } & 1. Salkowski test & + \\
\hline & & $\begin{array}{l}\text { 2. Liebermann } \\
\text { Burchard test }\end{array}$ & + \\
\hline 6 & Phenols & 1. Ferric chloride test & + \\
\hline 7 & Tannins & 1. Alkaline reagent & + \\
\hline \multirow[t]{3}{*}{8} & \multirow[t]{3}{*}{ Flavanoids } & 1. Gelatin test & + \\
\hline & & 2. Lead acetate test & + \\
\hline & & 3. Shinoda test & + \\
\hline \multirow[t]{3}{*}{9} & \multirow[t]{3}{*}{ Proteins } & 1. Xanthoproteic test & - \\
\hline & & 2. Ninhydrine test & - \\
\hline & & 3. Biuret test & - \\
\hline
\end{tabular}

Table.2 Pharmacological Screening for Antibacterial Activity

\begin{tabular}{|l|l|l|l|}
\hline Sl. No & Microorganism & $\begin{array}{l}\text { Test zone of inhibition } \\
(\mathbf{m m})\end{array}$ & $\begin{array}{l}\text { Standard zone of } \\
\text { inhibition } \mathbf{( m m})\end{array}$ \\
\hline 1 & E. coli & 40 & 38 \\
\hline 2 & Staphylococcus aureus & 41 & 36 \\
\hline 3 & Pseudomonas aeruginosa & 38 & 45 \\
\hline 4 & Basillus cerues & 40 & 35 \\
\hline
\end{tabular}


Figure.1 Jasminum grandiflorum Plant

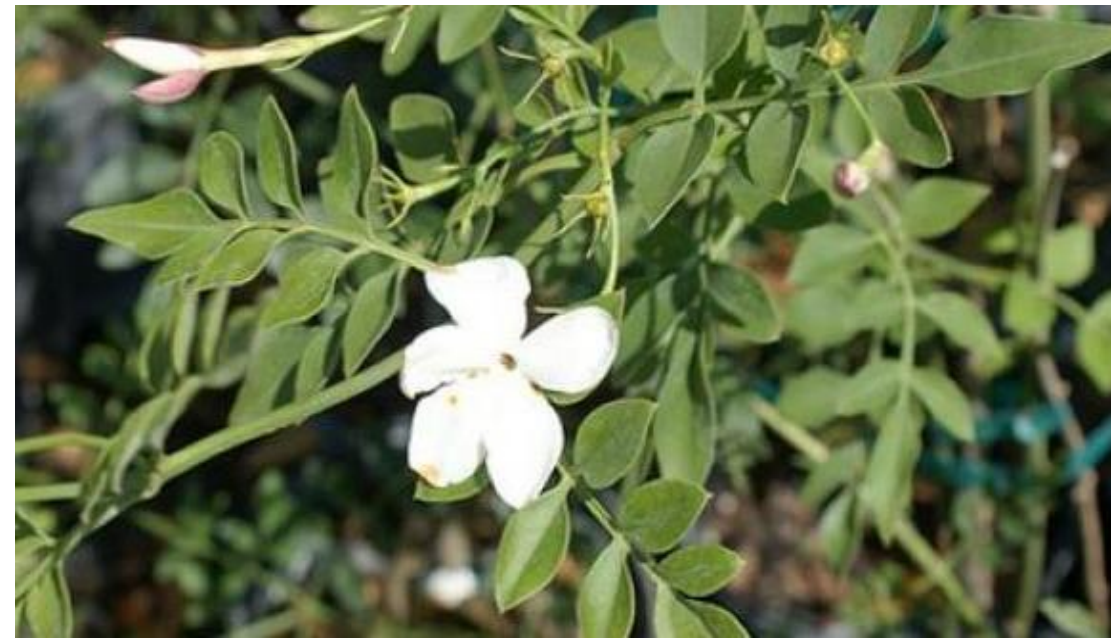

Figure.2 Pharmacological Screening for Antibacterial Activity

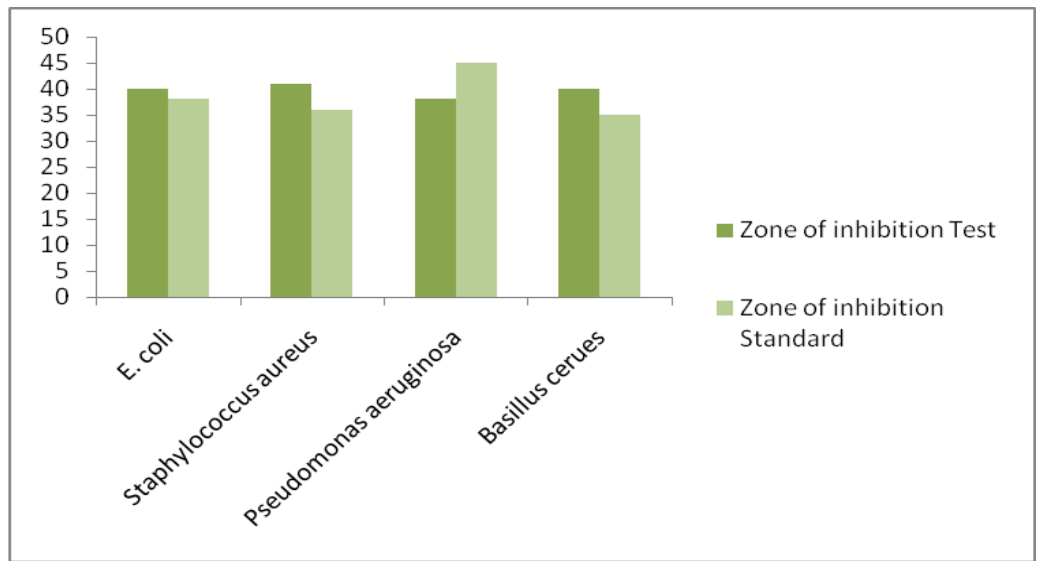

A gel provides a successful approach in delivering combination product; hence for the present study a gel system has designed to deliver the drug. The most significant part is the use of high performance polymer carbopol as the gelling agent. Physical, chemical and biological evaluation complies with the standard specification. The chemical investigation of gel showed the presence of various phytoconstituents like phytosterol, phenols, tannins, flavanoids, alkaloids, carbohydrates, saponins terpenes. The gel showed highest activity against $S$ aureus and showed significant activity against all organisms compared to standard drug ciprofloxacin.

\section{Conclusion}

In the present study gel was formulated from aqueous extracts of Jasminum grandiflorum, and evaluated its physical, chemical and biological properties. The physical evaluation of formulated gel for parameters like $\mathrm{pH}$, refractive index, specific gravity complies with the standard specification. The chemical investigation of gel showed the presence of various phytoconstituents like phytosterol, phenols, tannins, flavanoids, alkaloids, carbohydrates, saponins terpenes. The biological evaluation was done by testing the gel against various microorganisms and was found most effective against $S$ aureus. 


\section{References}

Asilbekova, D.T., Gusakova, S.D., Glushenkova, A.I. 1999. Conposition of the floral waxes of Rosa gallica, Jasminum grandiflorum, and viola odorata. Chem. Natural Products, 03(35): 327-333.

Aulton, M.E. 1995. Pharmaceutics the Science of Dosage Form Design;: First edition. ELBS Churchill Livingstone, 386.

Barry, B.W. 1983. Dermatological Formulations. Vol. 18. Marcel Deckker Inc. 296-340.

Gupta, P., Garg, S. 2002. Recent Adances in Semisolid Dosage Form for Dermatological Application. Pharma. Technol., 144-162.

Kolanjiappan, K., Manoharan, S. 2005. Chemo preventive efficacy and antilipid peroxidative potential of Jasminum grandiflorum Linn. On 7,12-dimethylbenz(a)anthraceneinduced rat mammary carcinogenesis. Fundamental \& Clin. Pharmacol., 19(6): 687-693.

Kulkarni, P.H., Ansari Shahida. 2004. The ayurvedic Plants Indian Medical Science series no. 132, Sri Satguru
Publications, Indological and Oriental Publications, A division book center, New Delhi, 191.

Lachman, L., Lieberman, H.A., Kanig, J.L. 1991. Theory and Practice of Industrial Pharmacy, $4^{\text {th }}$ edition, 1991, Verghese Publishing House, 534-563.

Priya Joy, Patric, R.D. 2008. Anti-bacterial activity studies of Jasminum grandiflorum and Jasminum sambac. Ethnobotanical leaflets, 12: 481-483.

Remington. 1995. The Science and Practice of Pharmacy. Vol.1.19 ${ }^{\text {th }}$ edition. 1995. Mark Publishing Company. 304-310.

Sadhu, S.K., Khan, M.S., Ohtsuki, T., Ishibashi, M. 2007. Secoiridoid components from Jasminum grandiflorum. Phytochem., 68(13): 1718-1721.

The wealth of India A Dictionary of Indian Raw Materials and Industrial Products, CSIR, New Delhi, 2004, 284-288.

Umamaheswari, M., Asok Kumar, K., Rathidevi, R., Sivashanmugam, A.T., Subbhardadevi, V., Ravi, T.K. 2007. Antiulcer and in vitro antioxidant activities of Jasminum grandiflorum Linn. J. Ethnopharmacol., 110(3): 464-470.

\section{How to cite this article:}

Lincy Joseph, Mathew George, Shweta Agrawal and Prabha Mathews. 2016. Formulation and Evaluation of Gel of Leaf Extract of Jasminum grandifloram. Int.J.Curr.Res.Aca.Rev.4(4): 6873. doi: http://dx.doi.org/10.20546/ijcrar.2016.404.008 